\section{An evaluation of coordination relationships during earthquake emergency rescue using entropy theory}

\author{
Uma avaliação das relações de coordenação \\ durante operações de resgate após terremoto \\ utilizando a teoria da entropia
}

\author{
Relación de coordinación en rescates de \\ emergencia tras terremotos, usando \\ la teoría de la entropía
}

\begin{abstract}
Emergency rescue after an earthquake is complex work which requires the participation of relief and social organizations. Studying earthquake emergency coordination efficiency can not only help rescue organizations to define their own rescue missions, but also strengthens interorganizational communication and collaboration tasks, improves the efficiency of emergency rescue, and reduces loss. In this paper, collaborative entropy is introduced to study earthquake emergency rescue operations. To study the emergency rescue coordination relationship, collaborative matrices and collaborative entropy functions are established between emergency relief work and relief organizations, and the collaborative efficiency of the emergency rescue elements is determined based on this entropy function. Finally, the Lushan earthquake is used as an example to evaluate earthquake emergency rescue coordination efficiency.
\end{abstract}

Rescue Work; Disaster Emergencies;

Natural Disasters
Huang Rong 1

Liang Xuedong 1

Zeng Guizhi 1

Ye Yulin 2

Wang $\mathrm{Da}^{3}$

\section{Resumo}

O resgate de emergência após terremoto é um trabalho complexo que exige a participação das organizações sociais e de ajuda. O estudo da eficiência da coordenação do resgate emergencial não apenas ajuda as organizações a definirem suas próprias missões de resgate, como também fortalece a comunicação entre as organizações e as tarefas de colaboração, além de melhorar a eficiência do trabalho de resgate e reduzir as perdas. O artigo usa a entropia colaborativa como base para estudar o trabalho de resgate emergencial após terremoto. Para estudar a relação de coordenação do resgate emergencial, são estabelecidas matrizes colaborativas e funções entrópicas colaborativas entre a ajuda de emergência e as organizações de ajuda; a eficiência colaborativa dos elementos de resgate emergencial é determinada com base nessa função de entropia. Finalmente, o terremoto de Lushan no sudoeste da China é usado como exemplo para avaliar a eficiência da coordenação do resgate emergencial após terremoto.

Trabalho de Resgate; Emergências em Desastres; Desastres Naturais 


\section{Introduction}

Earthquake emergency rescue needs to take place without delay or error, and requires close cooperation between emergency rescue organizations so that operations are carried out smoothly. Improvements in emergency rescue efficiency after an earthquake is the key to successful rescue operations, as it can not only enhance emergency rescue organizational and rescue task efficiency, but also strengthen aid organizations' cooperative abilities. Further, such improvements can reduce casualties, and lessen the country's economic and social burden. It is important to clarify the rescue mission's purpose, strengthen interagency communication, build procedures for the sharing of information and resources, determine measures for gathering missing information and urgently needed rescue resources, and improve the timeliness and safety of the emergency rescue, all of which can result in $1+1>2$ collaborative efficiency.

Synergy is a cooperative mode which seeks to achieve maximum effectiveness ${ }^{1}$. The application of theoretical cooperative aspects was first successfully applied to air traffic management in 1993, when the United States Federal Bureau of Aeronautics (Federal Aviation Administration) 2 sought to solve the problem of air traffic congestion by introducing collaborative decision making into the air traffic management system. After this success, the development of coordinated decision making led to a deeper collaborative relationship between aviation related managers in Europe ${ }^{3}$. Research into leadership, decision making, and the collaborative relationship between the government and aid organizations by Naim et al. 4 found that collaborative networking could improve emergency management efficiency by making more effective use of emergency resources. Turner ${ }^{5}$ and Quarantelli ${ }^{6}$ indicated that there are difficulties in communication between organizations, which can lead to reduced rescue efficiency. Better communication and collaboration can improve rescue efficiency. Quarantelli 7 put forward ten criteria for evaluating the management of community disasters. If all the ten criteria are met, it is very likely that any disaster will be managed competently. Comfort et al. 8 established a dynamic simulation system to evaluate the emergency response capability of a community. This research also demonstrated that obtaining core information improved disaster response efficiency, and increased the response organization network cooperation. Wu \& Zhang ${ }^{9}$ studied the factors which influenced emergency collaborative efficiency from the perspective of a multi agent using an example from the Hubei highway.
Deng \& Liu 10, when studying the Yushu (Qinghai, China) earthquake rescue process, proposed a coordinated emergency method and established a cooperative efficiency evaluation model focusing on the collaborative efficiency curve of the rescue teams, medical departments, traffic departments and associated organizations. Song 11 outlined an earthquake emergency collaborative logistics network based on CAS theory (Complex Adaption System) to build an earthquake emergency logistics network. Xie 12 studied the secondary disasters of an earthquake emergency management coordination mechanism. This work proposed that earthquake emergency management work should be divided according to the rescue phase and that rescue organizations be reasonably configured to reduce the possibility of secondary disasters.

Emergency coordination research to date has mostly focused on collaborative logistics networks and collaborative emergency management mechanisms, while less focus has been on the coordination efficiency of earthquake emergency rescue organizations. This paper examines earthquake emergency rescue work and the important organizations which participate in the rescue. Using graph theory, an analysis of the collaborative relationship between rescue organizations is conducted by introducing collaborative entropy theory to establish the collaborative emergency rescue evaluation model, to evaluate the earthquake emergency rescue synergy and to provide a reference for developing the earthquake emergency rescue coordination efficiency.

\section{Analysis of earthquake emergency rescue}

\section{Analysis of earthquake emergency rescue work}

Post-earthquake emergency rescue is a complex project, which involves many factors and links, and is closely related to all aspects of society, the economy, science and technology. Relief work includes the preparation and transportation of relief materials, road repairs, search and rescue operations, the treatment of casualties, and the organization of psychological counseling for populations. Since emergency rescue work is varied, there is a need for specialized technical personnel to ensure that rescue operations are conducted in a timely manner. Further, postdisaster emergency aid needs to be based on the scope and degree of the disaster. Generally however, a successful rescue operation requires that rescue workers are rapidly organized, all aspects 
of power are coordinated, enough supplies are available as soon as possible, advanced rescue equipment is immediately available, emergency medical supplies are adequately prepared, and relief materials are transported to the affected site in the fastest, most efficient and secure way.

Post-earthquake relief work includes the categories 13 shown in Figure 1.

\section{Analysis of earthquake emergency rescue organizations}

Post-earthquake emergency rescue work has two main participants: government funded rescue organizations and social forces such as local and non-governmental aid organizations. Government rescue organizations include: (1) the State Seismological Bureau, which in China is also known as the China Earthquake Administration, which leads and coordinates local Seismological Bureaus' earthquake predictions, disaster forecasts, post disaster damage assessments and the formulation of the earthquake relief work programs; (2) the Headquarters of the State Council for Earthquake Relief which gives guidance and advice to regional headquarters for earthquake relief and earthquake field work flow headquarters in disaster decisions, emergency plan formulation and emergency rescue work; (3) the
Emergency Command, whose main role when responding to an emergency is the provision of routine first aid, emergency management coordination, and emergency education training by providing leadership to teams from local rescue, health and epidemic prevention, infrastructure repair, psychological counseling and geological monitoring. Government aid organizations are usually the primary emergency rescue force, who undertake most of the emergency rescue work. The social forces 11 are mainly made up of local enterprises and public and non-governmental organizations. The earthquake emergency rescue organization classification is shown in Figure 2.

\section{Analysis of the relationship between cooperating organizations}

In graph theory, the chain, the in-tree and the out-tree are the three basic logical relationships in an information exchange department, which together make up the information interactivity flow chart. Three typical 14 collaborative rescue frameworks between emergency rescue organizations are defined in this paper. If each rescue has a leading organization to whom other institutions and organizations look to for advice and guidance, this emergency rescue logic is called a Chain. If the rescue logic has only one subse-

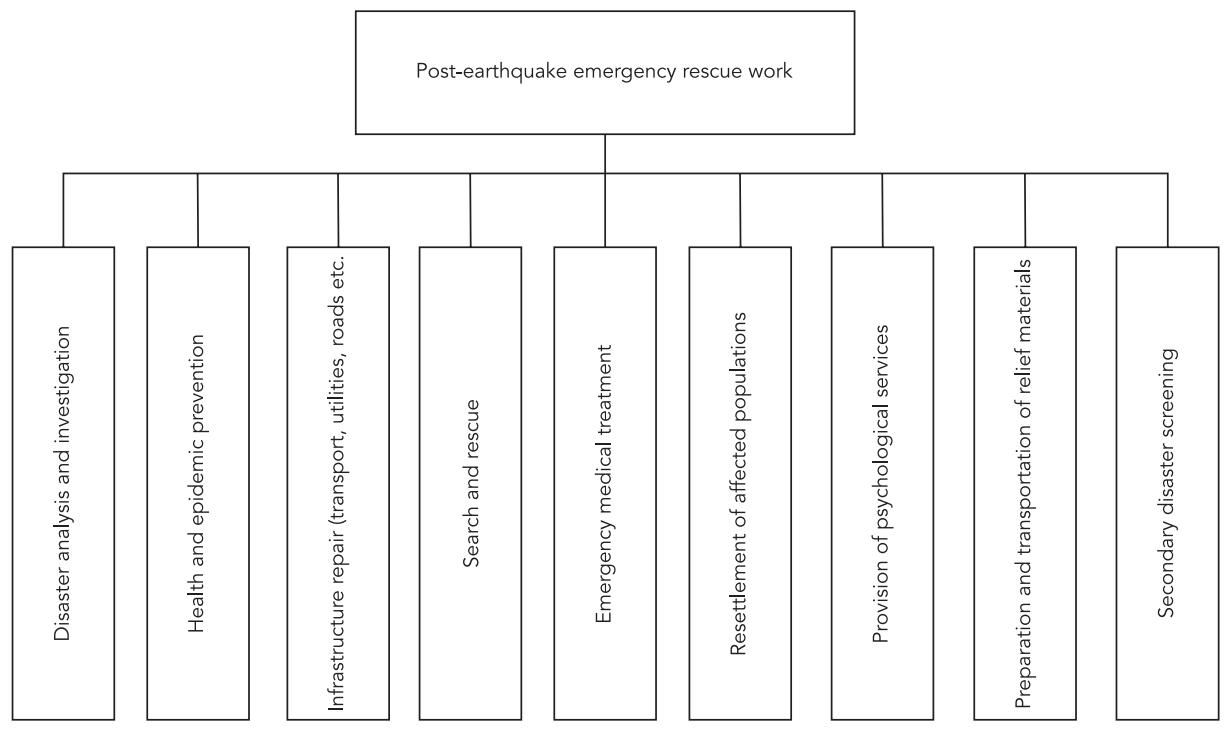


Figure 2

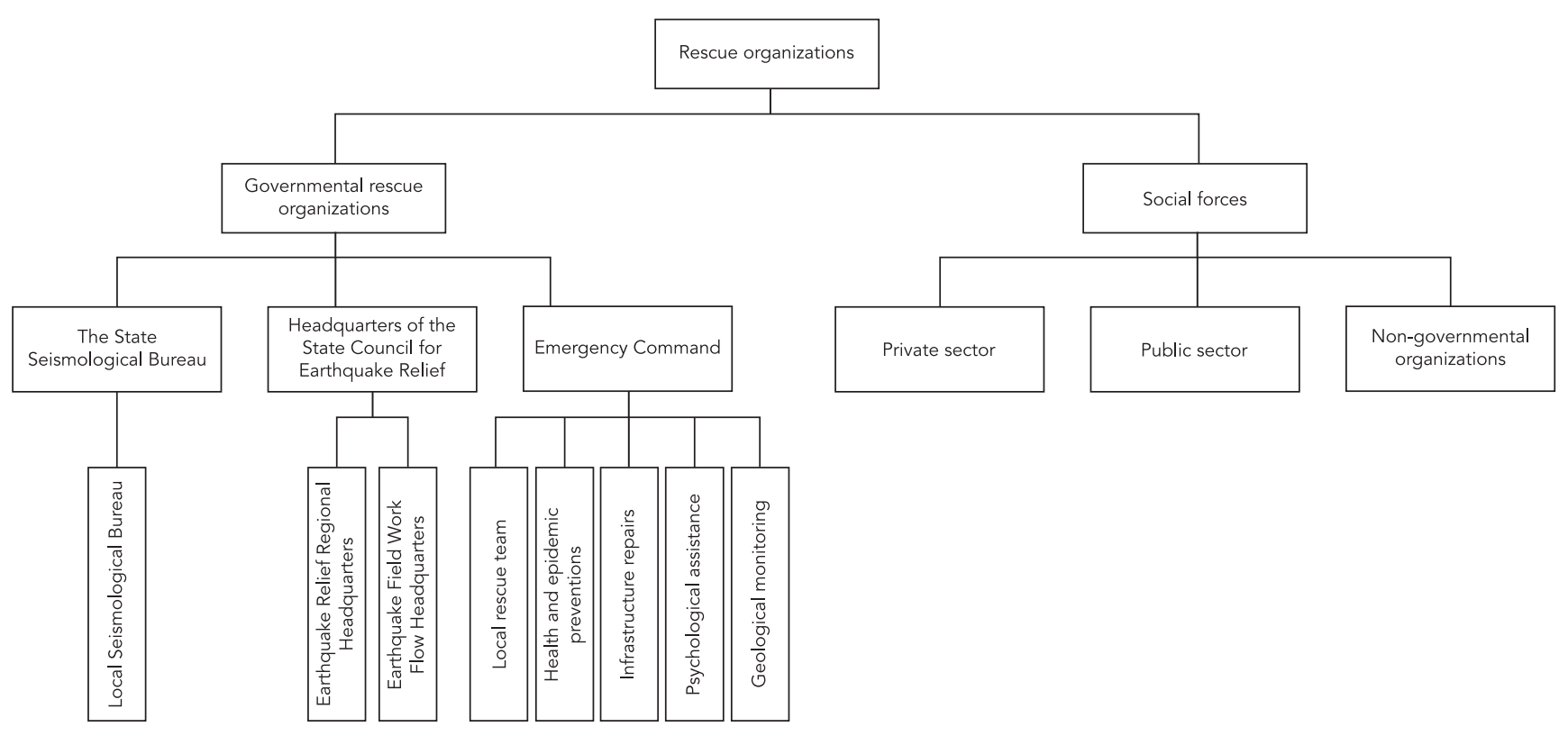

quent institution at most, the information interaction logic is called an In-tree. If the rescue logic has one pioneer institution, the emergency rescue logic is called the Out-tree. In Figure $3 a, 3 b$, and $3 \mathrm{c}$, the direct matrix structures show examples of the chain, the in-tree and the out-tree information interactions.

Figure 4 shows emergency rescue collaborative relationship diagrams for three logical structures, which reflect the coordination between the emergency rescue mechanism and the emergency rescue work, with each of these three structures having different rescue objectives.

\section{Emergency rescue coordination evaluation model}

Song et al. 15 used management entropy theory to evaluate enterprise organizational system cooperation. They defined the collaborative parameters for an inherent collaborative enterprise organization as: management level, management span, collaborative span, coordinated trajectory, coordination function and coordination efficiency. The authors examined the multidimensional cooperative structure by investigating the cooperative and collaborative functions, from which a collaborative information entropy evaluation mathematical model was established 15 . Jiang \& Yue 16 studied the efficiency between enterprise management activities to propose an entropy theory. By constructing a cooperative evaluation structure for an enterprise business management system, they drew up a cooperative influence matrix which looked at the management business and synergy entropy function at each management level, and, based on the coordination degree, measured the synergy entropy of the various levels of the management structure and from these were able to develop an efficiency evaluation model. In this study, this entropy theory is applied to earthquake emergency rescue collaboration.

The emergency rescue elements; emergency rescue organization, emergency relief work; are compared, and a collaborative matrix established between each emergency rescue element.

$\varepsilon=\left[\begin{array}{cccccc}\mu_{11} & \mu_{12} & \cdots & \mu_{1 j} & \cdots & \mu_{1 n} \\ \mu_{21} & \mu_{22} & \cdots & \mu_{2 j} & \cdots & \mu_{2 n} \\ \vdots & \vdots & \vdots & \vdots & \vdots & \vdots \\ \mu_{i 1} & \mu_{i 2} & \cdots & \mu_{i j} & \cdots & \mu_{i n} \\ \vdots & \vdots & \vdots & \vdots & \vdots & \vdots \\ \mu_{n 1} & \mu_{n 2} & \cdots & \mu_{n j} & \cdots & \mu_{n n}\end{array}\right]$ 
EARTHQUAKE EMERGENCY RESCUE COORDINATION RELATIONSHIPS

951

Figure 3

Chain, in-tree and out-tree rescue logic emergency organization.

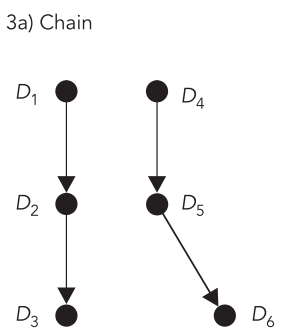

Bb) In-tree

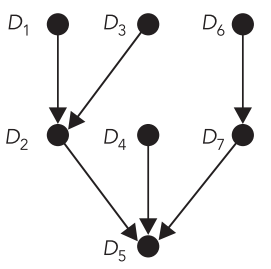

Bc) Out-tree

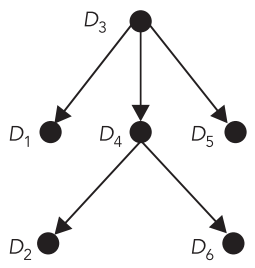

Figure 4

Emergency rescue coordination relationships.

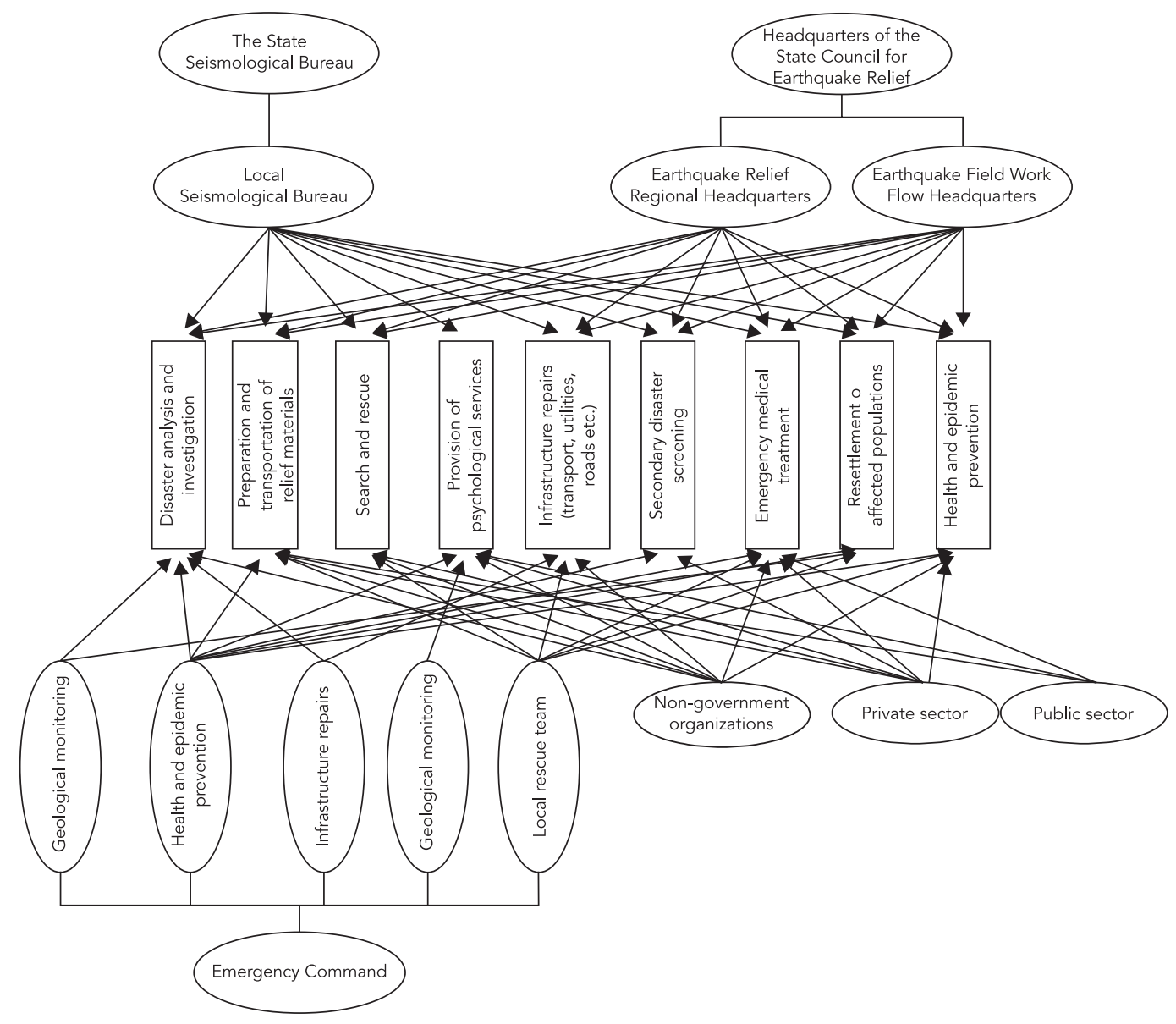

Cad. Saúde Pública, Rio de Janeiro, 31(5):947-959, mai, 2015 
$\mu_{i j}=\left\{\begin{array}{c}1 \text { Element } i \text { and } j \text { collaborate on emergency rescue information sharing } \\ 0 \quad \text { other wise }\end{array}, i \neq j\right.$ (formula 2)
$\mu_{i j}=\left\{\begin{array}{c}1 \text { The bottom level of emergency rescue elements } \\ 0 \text { Other layer level of emergency rescue elements }\end{array}, i=j\right.$ (formula 3)

$Y_{q}$ is the number of emergency rescue elements in a synergistic state, and $Y_{f}$ is the number of emergency rescue elements in a non-cooperative state, so then the total number of emergency rescue elements is $Y=Y_{q}+Y_{f}$. If $P\left(Y_{q}\right)=Y_{q} / Y$, then according to the relationship between probability and Shannon's entropy, the coordination entropy of the emergency rescue collaborative elements is:

$H_{i j q}=-\sum \frac{Y_{q}}{Y} \log \frac{Y_{q}}{Y}$

(formula 4)

and the collaborative entropy for the non-cooperative elements of the emergency rescue is:

$H_{i j f}=-\sum \frac{Y_{f}}{Y} \log \frac{Y_{f}}{Y}$

(formula 5)

The collaborative degree $C$ indicates the degree of coordination between the emergency rescue elements and other emergency relief elements. $H_{\max }$ represents the maximum collaborative entropy in the emergency rescue coordination factor on the same level, so:

$C=1-\frac{H_{i j q}}{H_{\text {max }}}$

(formula 6)

Collaborative efficiency R can be represented as:

$R=1-\frac{H_{i j q}}{H_{i j}}=1-\frac{H_{i j q}}{H_{i j q}+H_{i j f}}$

(formula 7)

The overall collaborative entropy for the emergency rescue factors on all levels is:

$$
B=\sum H_{i j}
$$

(formula 8)

The collaborative degree $\mathrm{C}$ of $\mathrm{B}$ is:

$C_{B}=\Sigma C\left(S_{i}\right) / n,(n=1,2, \ldots n)$

(formula 9)

Collaborative efficiency R of B is:

$R_{B}=1-H_{i j q}(B) /\left(H_{i j q}(B)+H_{i j f}(B)\right) \quad($ formula 10$)$

Depending on the nature of the log functions and probability, the more emergency rescue coordination elements there are in the emergency rescue coordination matrix, the closer the situation is to a full cooperative state; conversely, the fewer emergency response elements there are, the closer the situation is to a non-cooperative state. In other words, the higher the collaborative efficiency $\mathrm{R}$, the better the coordination amongst emergency rescue elements.

\section{Case analysis}

In China, there have been several significant earthquake disasters in the past decade. Since the Tangshan earthquake in 1976, there have been the Wenchuan earthquake in 2008 and the Yushu earthquake in 2010. On 20 April 2013, there was a 7.0 earthquake in Lushan County in Yaan Sichuan, which impacted an areas of $12,500 \mathrm{~km}^{2}$, and involved huge losses, including 1.52 million people injured and 17,000 collapsed houses. Every emergency rescue organization had taken action as soon as the earthquake ocurred: the State Seismological bureau and Sichuan government started the first level emergency response and sent the fieldwork team to the disaster area. The National Disaster Reduction Committee and the Civil Affairs started the third level emergency response. The State Council issued an emergency rescue notice on April 21. The Health and Family Planning Commission started medical rescues on April 20 and established the national health emergency team. More than 180 medical personnel were mobilized and an automotive mobile hospital was sent to the disaster area. The China Red Cross Society allocated 500 tents to the affected areas. The Lushan People's Hospital established the medical command center, many hospitals including Sichuan People's Hospital started emergency plans, set up temporary headquarters, defined a clear treatment process and a good preparation for emergency medical rescue.

Because of the tragic losses incurred both socially and economically, post-disaster emergency rescue operations have attracted the attention of many scholars, with improvements in earthquake emergency rescue efficiency being the main focus. Wang 17 researched the evaluation and choice of emergency collaborative decision-making using collaborative entropy theory to construct an emergency collaborative decision-makers synergy model, which allowed for an investigation of the cooperative evaluation between the decision subjects.

\section{Emergency rescue coordination evaluation}

From Figures 2 and 4, and knowledge of the emergency rescue organization and the internal coordination of the emergency rescue work, the cooperative influence matrix for the emergency rescue organizations can be established. $\varepsilon_{1}$ is the 
synergistic influence matrix for the six government rescue organizations and the social forces; $\varepsilon_{12}$ is the synergistic influence matrix for the two aid agencies under the State Council earthquake relief command; $\varepsilon_{13}$ is the synergistic influence matrix for the five rescue organizations under Emergency Command; and $\varepsilon_{2}$ is the collaborative influence matrix for the nine elements of emergency rescue work, so:

$\varepsilon_{1}=\left[S_{i}, S_{j}\right]_{6 \times 6}=\left(\mu_{i j}\right)_{6 \times 6}$

$\varepsilon_{12}=\left[S_{2 i}, S_{2 j}\right]_{2 \times 2}=\left(\mu_{i j}\right)_{2 \times 2}$

$\varepsilon_{13}=\left[S_{3 i}, S_{3 j}\right]_{5 \times 5}=\left(\mu_{i j}\right)_{5 \times 5}$

$\varepsilon_{2}=\left[T_{i}, T_{j}\right]_{9 \times 9}=\left(\mu_{i j}\right)_{9 \times 9}$

From information provided as to the actual situation at the Lushan earthquake, members of the project group determined the internal cooperative relationship between the emergency rescue organizations and the internal cooperative relationship within the emergency rescue work as shown in Figures 5, 6 and 7, based on the formula presented in (1) - (3), which was converted into a cooperative influence matrix as shown below:

$\varepsilon_{1}=\left[\begin{array}{llllll}0 & 1 & 1 & 0 & 0 & 0 \\ 1 & 0 & 1 & 1 & 1 & 1 \\ 1 & 1 & 0 & 1 & 1 & 1 \\ 0 & 1 & 1 & 0 & 1 & 1 \\ 0 & 1 & 1 & 1 & 0 & 1 \\ 0 & 1 & 1 & 1 & 1 & 0\end{array}\right]$

$\varepsilon_{12}=\left[\begin{array}{ll}1 & 1 \\ 1 & 1\end{array}\right]$

$\varepsilon_{2}=\left[\begin{array}{lllllllll}0 & 1 & 1 & 1 & 1 & 1 & 1 & 1 & 1 \\ 1 & 0 & 0 & 0 & 1 & 1 & 0 & 1 & 1 \\ 1 & 0 & 0 & 0 & 0 & 1 & 0 & 1 & 1 \\ 1 & 0 & 0 & 0 & 1 & 1 & 1 & 1 & 0 \\ 1 & 1 & 0 & 1 & 0 & 1 & 1 & 1 & 0 \\ 1 & 1 & 1 & 1 & 1 & 0 & 1 & 1 & 1 \\ 1 & 0 & 0 & 1 & 1 & 1 & 0 & 0 & 0 \\ 1 & 1 & 1 & 1 & 1 & 1 & 0 & 0 & 1 \\ 1 & 1 & 1 & 0 & 0 & 1 & 0 & 1 & 0\end{array}\right]$

$$
\varepsilon_{13}=\left[\begin{array}{lllll}
1 & 1 & 1 & 1 & 1 \\
1 & 1 & 0 & 0 & 1 \\
1 & 0 & 1 & 0 & 1 \\
1 & 0 & 0 & 1 & 0 \\
1 & 1 & 1 & 0 & 1
\end{array}\right]
$$

From formulas $(4) \sim(10)$, the cooperative relationship between the emergency rescue work and emergency rescue organizations were respectively computed, the results of which are shown in Tables 1 and 2. In Table 1, the number of the organizations that has the cooperative relationship with the State Seismological Bureau is 2, then $Y_{q}=2$, the number of contrary is $Y_{f}=4$ then $Y=4+2=6$, with no consideration of the organizations that under every upper organization, $j=1$, so:

$H_{i q}\left(S_{1}\right)=-\frac{Y_{q}}{Y} \log \frac{Y_{q}}{Y}=-2 / 6 \log (2 / 6)=0.1590 \quad$ (formula 4)

$H_{i f}\left(S_{1}\right)=-\frac{Y_{\mathrm{f}}}{Y} \log \frac{Y_{\mathrm{f}}}{Y}=4 / 6 \log (4 / 6)=0.1174$ (formula 5)

Form all the result of $\mathrm{H}_{\mathrm{ijq}}$, we can see $\mathrm{H}_{\max }=$ 0.1590, so:

$C_{s_{1}}=1-\frac{H_{i q}\left(S_{1}\right)}{H_{\max }}=1-0.1590 / 0.1590=0$ (formula 6)

$R_{s_{1}}=1-\frac{H_{i q}\left(S_{1}\right)}{H_{i q}\left(S_{1}\right)+H_{i f}\left(S_{1}\right)}=1-0.1590 /(0.1590+0.1174)=0.4247$ (formula 7)

$H_{i q}\left(B_{1}\right)=\sum_{i=1}^{6} H_{i q}=0.6432$ (formula 8)

$H_{i f}\left(B_{1}\right)=\sum_{i=1}^{6} H_{i f}=0.8538$ (formula 8)

$C_{B_{1}}=\Sigma C\left(S_{i}\right) / 6=0.3258$ (formula 9 )

$R_{B_{1}}=1-H_{i q}\left(B_{1}\right) /\left(H_{i q}\left(B_{1}\right)+H_{i f}\left(B_{1}\right)\right)=0.5703$ (formula 10)

The method to calculate the other dates in Table1, 2, 3, 4 is the same with the method above.

To research this collaborative relationship, rescue organizations were coded as to whether or not they participated in emergency rescue work, with 1 indicating that the organization was directly or indirectly involved in the emergency rescue work, and 0 indicating that the organization was not involved in the emergency rescue work.

We thereby establish the emergency cooperative matrix between the rescue organizations involved in the Lushan earthquake and the emergency rescue work. 
Level 1 for emergency rescue organizations is $\varepsilon_{1}=\left(S_{i}, T_{i}\right)_{6 \times 9}$, and level 1 for emergency rescue work is $\varepsilon_{2}=\left(S_{i j}, T_{i}\right)_{8 \times}$, so we have the following synergistic influence matrix:

$\varepsilon_{1}=\left[\begin{array}{llllll}1 & 1 & 1 & 0 & 0 & 1 \\ 1 & 1 & 1 & 1 & 0 & 1 \\ 1 & 1 & 1 & 1 & 0 & 1 \\ 1 & 1 & 1 & 0 & 0 & 1 \\ 1 & 1 & 1 & 1 & 1 & 1 \\ 1 & 1 & 1 & 0 & 0 & 0 \\ 1 & 0 & 1 & 1 & 1 & 1 \\ 1 & 1 & 1 & 1 & 1 & 1 \\ 1 & 1 & 1 & 1 & 0 & 0\end{array}\right]$

$\varepsilon_{2}=\left[\begin{array}{llllllll}1 & 1 & 1 & 0 & 1 & 1 & 0 & 1 \\ 1 & 1 & 1 & 1 & 1 & 0 & 0 & 0 \\ 1 & 1 & 1 & 1 & 0 & 1 & 0 & 0 \\ 1 & 1 & 1 & 1 & 0 & 0 & 0 & 0 \\ 1 & 1 & 1 & 1 & 1 & 0 & 0 & 0 \\ 1 & 1 & 1 & 1 & 1 & 0 & 0 & 0 \\ 1 & 0 & 0 & 0 & 1 & 0 & 1 & 0 \\ 1 & 1 & 1 & 1 & 1 & 0 & 0 & 0 \\ 1 & 1 & 1 & 0 & 1 & 0 & 0 & 1\end{array}\right]$

From Equations (4) - (8), we calculated the synergy between the emergency rescue work and the emergency rescue organizations, the results which are shown in Tables 3 and 4.
From an analysis of the cooperative relationship between the coordination degree and coordination efficiency at the Lushan earthquake emergency rescue, we evaluated the coordination efficiency of the earthquake's emergency rescue. Figures 8 and 9 show: (1) for the collaborative efficiency of the second rescue organizations, except for the S1 National Earthquake Administration, the difference is small, at around 0.5 to 0.6 , so a difference in emergency rescue organization coordination ability is not obvious; (2) the third layer Rescue Organization collaborative efficiency compared to that of the second layer has an obvious difference with a minimum of 0.5446, yet the collaborative efficiency of the Health and Epidemic Prevention, Infrastructure repair, Psychological Counseling, the local Seismological Bureau, Earthquake Relief Regional Headquarters and Earthquake Field Work Flow Headquarters all respectively reached 1; (3) the collaborative efficiency of the rescue work is high with a maximum of 0.7 and a minimum of 0.4754 , which indicates that disaster analysis and investigation is the basis of other rescue work, but the resettlement of affected people is for relief purposes; (4) the volatility of the cooperative efficiency ofregularizar the second rescue organization and emergency rescue work is greater than the others with a maximum of 1 and a minimum of 0.5753 , but the collaborative efficiency of the third rescue organization and relief work is lower than the second layer's, with a maximum of 0.6163 and a minimum of 0.5 , which indicates

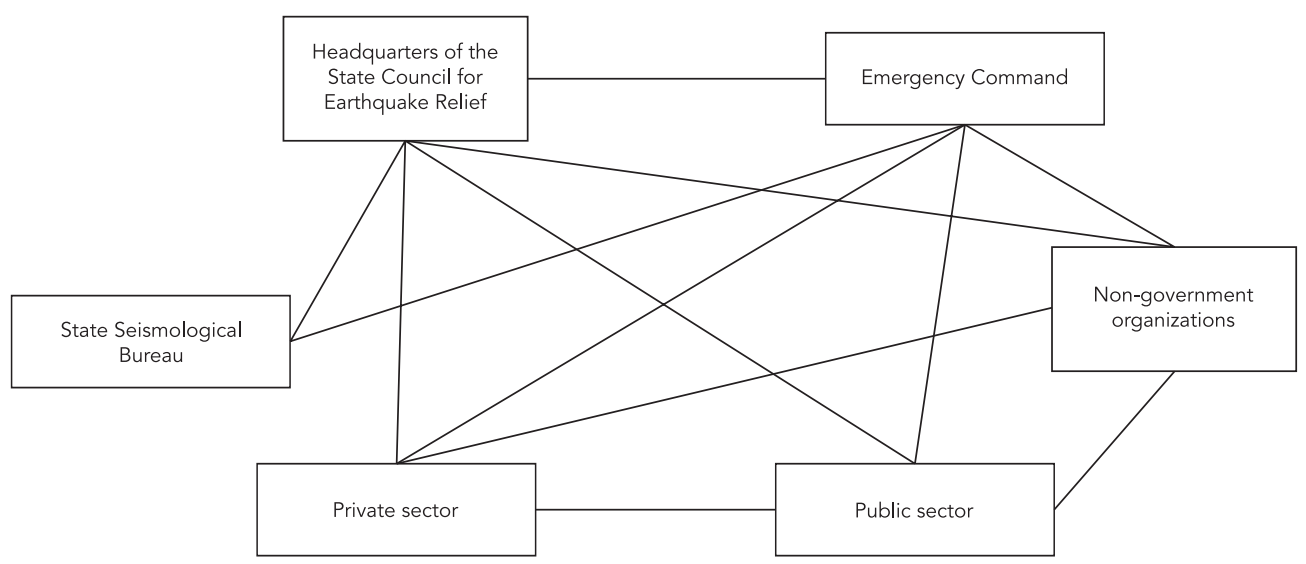




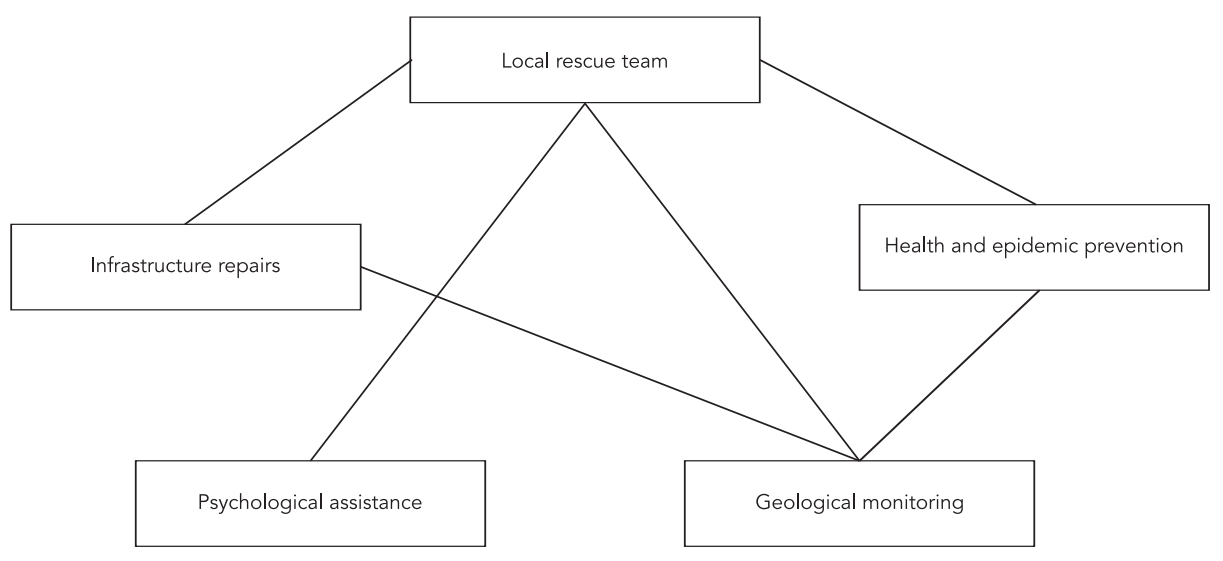

Figure 7

Collaborative relationships within the emergency rescue work.

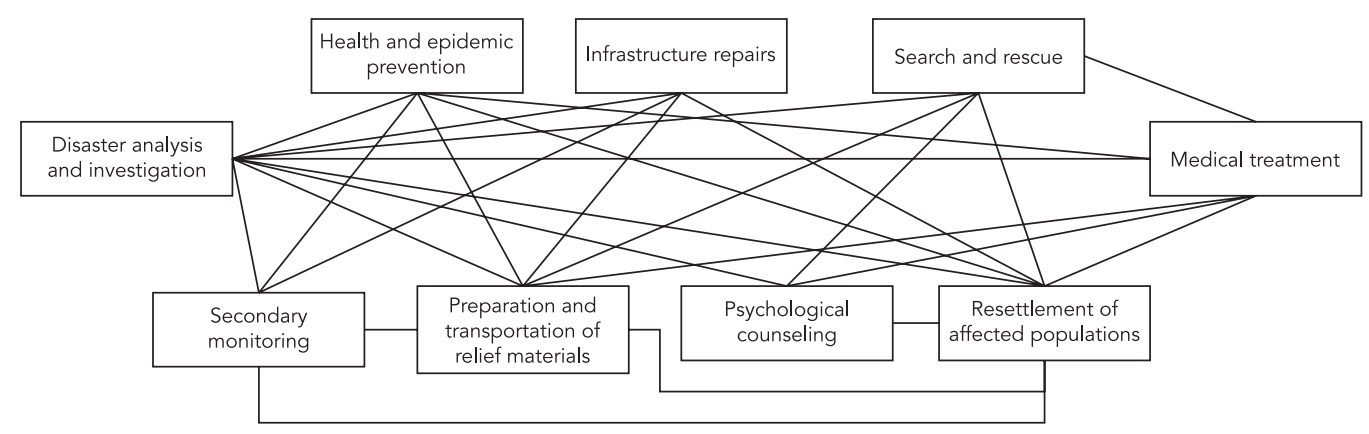

that the next layer is concerned mainly with the implementation of the emergency rescue teams; and (5) overall, the total collaborative efficiency of the emergency rescue elements is high, at more than 0.5 , with the maximum collaboration efficiency being between the second rescue organization and relief work at 0.8115 , and the minimum collaboration efficiency being between the third rescue organization and relief work at 0.5482 .

$\mathrm{R} 1$ represents the collaborative efficiency within the second layer of emergency rescue organizations; R2 represents the collaborative efficiency within the third layer of emergency rescue organizations; R3 represents the internal coordination efficiency for emergency relief work; R4 represents the collaborative efficiency between the rescue organizations and rescue work; and R5 represents the collaborative efficiency between the third layer rescue organizations and rescue work.

\section{Conclusion}

This paper outlined a cooperative framework for post-earthquake emergency rescue work, in 
Table 1

The internal emergency rescue organization synergy index.

\begin{tabular}{|c|c|c|c|c|c|c|c|c|}
\hline & \multicolumn{8}{|c|}{ Emergency rescue organizations } \\
\hline & $\mathrm{S}_{1}$ & $\mathrm{~S}_{2}$ & $\mathrm{~S}_{3}$ & $\mathrm{~S}_{4}$ & $\mathrm{~S}_{5}$ & $S_{6}$ & $\mathrm{~B}_{1}$ & \\
\hline Collaborative entropy $\mathrm{H}_{\mathrm{ijq}}$ & 0.1590 & 0.0660 & 0.0660 & 0.1174 & 0.1174 & 0.1174 & 0.6432 & \\
\hline Collaborative entropy $\mathrm{H}_{\mathrm{ijf}}$ & 0.1174 & 0.1297 & 0.1297 & 0.1590 & 0.1590 & 0.1590 & 0.8538 & \\
\hline Collaborative degreeC & 0 & 0.5850 & 0.5850 & 0.2616 & 0.2616 & 0.2616 & 0.3258 & \\
\hline \multirow[t]{2}{*}{ Collaborative efficiencyR } & 0.4247 & 0.6627 & 0.6627 & 0.5753 & 0.5753 & 0.5753 & 0.5703 & \\
\hline & $\mathrm{S}_{21}$ & $\mathrm{~S}_{22}$ & $\mathrm{~S}_{31}$ & $\mathrm{~S}_{32}$ & $\mathrm{~S}_{33}$ & $\mathrm{~S}_{34}$ & $\mathrm{~S}_{35}$ & $\mathrm{~B}_{2}$ \\
\hline Collaborative entropy $\mathrm{H}_{\mathrm{ijq}}$ & 0 & 0 & 0 & 0.1331 & 0.1331 & 0.1331 & 0.0775 & 0.4768 \\
\hline Collaborative entropyH $\mathrm{H}_{\mathrm{ijf}}$ & 0 & 0 & 0 & 0.1592 & 0.1592 & 0.1592 & 0.1398 & 0.6174 \\
\hline Collaborative degreeC & 1 & 1 & 1 & 0 & 0 & 0 & 0.4177 & 0.4882 \\
\hline Collaborative efficiencyR & 1 & 1 & 1 & 0.5446 & 0.5446 & 0.5446 & 0.6434 & 0.5642 \\
\hline
\end{tabular}

$\mathrm{S}_{1}$ : The State Seismological Bureau; $\mathrm{S}_{2}$ : The Headquarters of the State Council for Earthquake Relief; $\mathrm{S}_{3}$ : The Emergency Command; $\mathrm{S}_{4}$ : Private sector; $\mathrm{S}_{5}$ : Public sector; $\mathrm{S}_{6}$ : Non-governmental organizations; $\mathrm{B}_{1}$ : total collaboration of $\mathrm{Si}_{\text {; }}$

$\mathrm{S}_{21}$ : Eathquake Relief Regional Headquarters; $\mathrm{S}_{22}$ : Earthquake Field Work Flow Headquarters; $\mathrm{S}_{31}$ : local rescue team;

$\mathrm{S}_{32}$ : health and epidemic prevention; $\mathrm{S}_{33}$ : infrastructure repairs; $\mathrm{S}_{34}$ : psychological assistance; $\mathrm{S}_{35}$ : geological

monitoring; $\mathrm{B}_{2}$ : total collaboration of Sij.

Table 2

The internal post-earthquake emergency rescue work synergy index.

\begin{tabular}{|c|c|c|c|c|c|c|c|c|c|c|}
\hline & \multicolumn{10}{|c|}{ Post-earthquake emergency rescue work } \\
\hline & $\mathrm{T}_{1}$ & $\mathrm{~T}_{2}$ & $\mathrm{~T}_{3}$ & $\mathrm{~T}_{4}$ & $\mathrm{~T}_{5}$ & $T_{6}$ & $\mathbf{T}_{7}$ & $\mathrm{~T}_{8}$ & $\mathrm{~T}_{9}$ & $\mathrm{~B}_{3}$ \\
\hline Collaborative entropy $\mathrm{H}_{\mathrm{ijq}}$ & 0.0455 & 0.1418 & 0.1565 & 0.1418 & 0.1174 & 0.0455 & 0.1565 & 0.0849 & 0.1418 & 1.0317 \\
\hline Collaborative entropyH $\mathrm{H}_{\mathrm{ijf}}$ & 0.1060 & 0.1565 & 0.1418 & 0.1565 & 0.1590 & 0.1060 & 0.1418 & 0.1452 & 0.1565 & 1.2693 \\
\hline Collaborative degreeC & 0.7093 & 0.0939 & 0 & 0.0939 & 0.2498 & 0.7093 & 0 & 0.4575 & 0.0939 & 0.2675 \\
\hline Collaborative efficiencyR & 0.7000 & 0.5246 & 0.4754 & 0.5246 & 0.5753 & 0.7000 & 0.4754 & 0.6310 & 0.5246 & 0.5516 \\
\hline
\end{tabular}

$T_{1}$ : disaster analysis and investigation; $T_{2}$ : health and epidemic prevention; $T_{3}$ : infrastructure repair; $T_{4}$ : search and rescue; $T_{5}$ : emergency medical treatment; $T_{6}$ : resettlement of affected populations; $T_{7}$ : provision of psychological services; $T_{8}$ : preparation and transportation of relief materials; $T_{9}$ : secondary disaster screening; $\mathrm{B}_{3}$ : total collaboration of $\mathrm{T}_{\mathrm{i}}$.

which the earthquake emergency rescue organizations are classified based on graph theory and the synergies analyzed. By applying coordinates from entropy theory into the elements of earthquake emergency rescue, an evaluation model for emergency collaborative efficiency was built. The collaborative relationship between emergency rescue work and emergency rescue organizations and with other organizations was researched. Data from the earthquake emergency rescue operations from the recent Lushan earthquake were used as an example to measure the coordination efficiency. The results showed that the coordination efficiency of the emergency rescue elements was relatively high. Emergency relief work is critical after the event, so the study of emergency rescue synergistic elements can provide a valuable reference for earthquake emergency rescue coordination and improve the efficiency of earthquake emergency rescue. It can also speed up the allocation of emergency medical supplies, ensure that the injured are treated as soon as possible, and reduce the mortality rate. Effective rescue collaboration can ensure that the health and epidemic prevention in affected areas goes quickly and effectively, keep the collective health of disaster areas and prevent secondary disasters. A model for earthquake emergency rescue coordination and public health in disaster areas will be the subject of further research. 
Synergy index for emergency rescue organizations, level 1 and emergency rescue work.

\begin{tabular}{lccccccccccc}
\hline & \multicolumn{1}{c}{ Post-earthquake emergency rescue work } \\
& $\mathrm{T}_{\mathbf{1}}$ & $\mathrm{T}_{\mathbf{2}}$ & $\mathrm{T}_{\mathbf{3}}$ & $\mathrm{T}_{\mathbf{4}}$ & $\mathrm{T}_{\mathbf{5}}$ & $\mathrm{T}_{\mathbf{6}}$ & $\mathrm{T}_{\mathbf{7}}$ & $\mathrm{T}_{\mathbf{8}}$ & $\mathrm{T}_{\mathbf{9}}$ & $\mathbf{B}_{\mathbf{4}}$ \\
\hline Collaborative entropyH $_{\mathrm{ijq}}$ & 0.1174 & 0.0660 & 0.0660 & 0.1174 & 0 & 0.1505 & 0.0660 & 0 & 0.1174 & 0.7007 \\
Collaborative entropyH $_{\mathrm{ijf}}$ & 0.1590 & 0.1297 & 0.1297 & 0.159 & 1 & 0.1505 & 0.1297 & 1 & 0.1590 & 3.0166 \\
Collaborative entropyC & 0.2199 & 0.5615 & 0.5615 & 0.2199 & 1 & 0 & 0.5615 & 1 & 0.2199 & 0.4827 \\
Collaborative efficiencyR & 0.5753 & 0.6627 & 0.6627 & 0.5753 & 1 & 0.5000 & 0.6627 & 1 & 0.5753 & 0.8115 \\
\hline
\end{tabular}

$T_{1}$ : disaster analysis and investigation; $T_{2}$ : health and epidemic prevention; $T_{3}$ : infrastructure repair; $T_{4}:$ search and rescue; $T_{5}$ : emergency medical treatment; $\mathrm{T}_{6}$ : resettlement of affected populations; $T_{7}$ : provision of psychological services; $T_{8}$ : preparation and transportation of relief materials; $T_{9}$ : secondary disaster screening; $\mathrm{B}_{4}$ : total collaboration of $\mathrm{T}_{\mathrm{i}}$

Table 4

Synergy index for emergency rescue organizations level 2 and emergency rescue work 4.2 Emergency rescue coordination analysis.

\begin{tabular}{lccccccccccc}
\hline & & \multicolumn{7}{c}{ Post-earthquake emergency rescue work } \\
& $\mathrm{T}_{\mathbf{1}}$ & $\mathrm{T}_{\mathbf{2}}$ & $\mathrm{T}_{\mathbf{3}}$ & $\mathrm{T}_{\mathbf{4}}$ & $\mathrm{T}_{\mathbf{5}}$ & $\mathrm{T}_{\mathbf{6}}$ & $\mathrm{T}_{\mathbf{7}}$ & $\mathrm{T}_{\mathbf{8}}$ & $\mathrm{T}_{\mathbf{9}}$ & $\mathbf{B}_{\mathbf{5}}$ \\
\hline Collaborative entropyH $_{\text {ijq }}$ & 0.0937 & 0.1276 & 0.1276 & 0.1505 & 0.1276 & 0.1276 & 0.1597 & 0.1276 & 0.1276 & 1.1695 \\
Collaborative entropyH $_{\text {ijf }}$ & 0.1505 & 0.1597 & 0.1597 & 0.1505 & 0.1597 & 0.1597 & 0.1597 & 0.1597 & 0.1597 & 1.4189 \\
Collaborative entropyC & 0.4133 & 0.2010 & 0.2010 & 0.0576 & 0.2010 & 0.2010 & 0.0000 & 0.2010 & 0.2010 & 0.1863 \\
Collaborative efficiencyR & 0.6163 & 0.5559 & 0.5559 & 0.5000 & 0.5559 & 0.5559 & 0.5000 & 0.5559 & 0.5559 & 0.5482 \\
\hline
\end{tabular}

$T_{1}$ : disaster analysis and investigation; $T_{2}$ : health and epidemic prevention; $T_{3}$ : infrastructure repair; $T_{4}$ : search and rescue; $T_{5}$ : emergency medical treatment; $\mathrm{T}_{6}$ : resettlement of affected populations; $\mathrm{T}_{7}$ : provision of psychological services; $\mathrm{T}_{8}$ : preparation and transport of relief materials; $T_{9}$ : secondary disaster screening; $B_{5}$ : total collaboration of $T_{i}$.

Figure 8

Coordination efficiency within emergency rescue organizations.

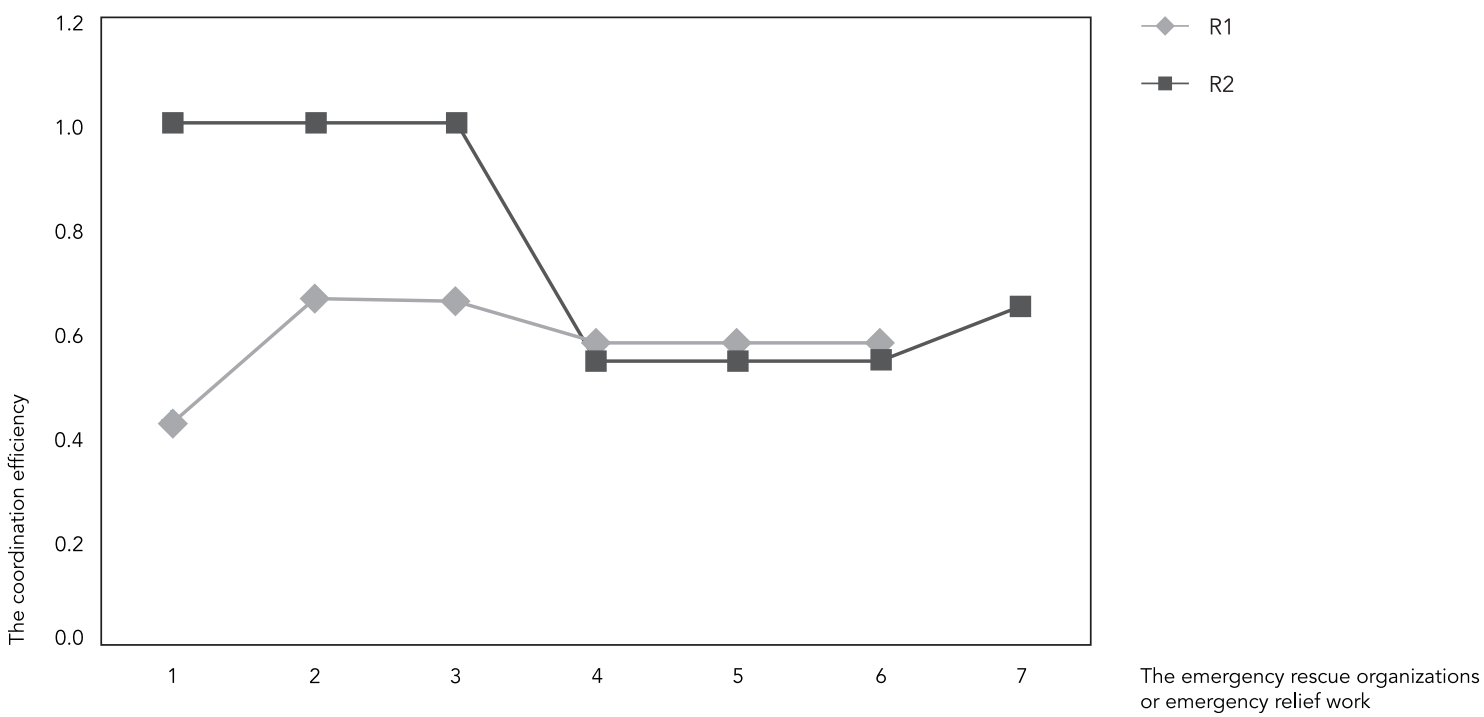

R1: represents the collaborative efficiency within the second layer of emergency rescue organizations; R2: represents the collaborative efficiency within the third layer of emergency rescue organizations. 
Figure 9

Coordination efficiency betwween emergency rescue organizations and emergency relief work.

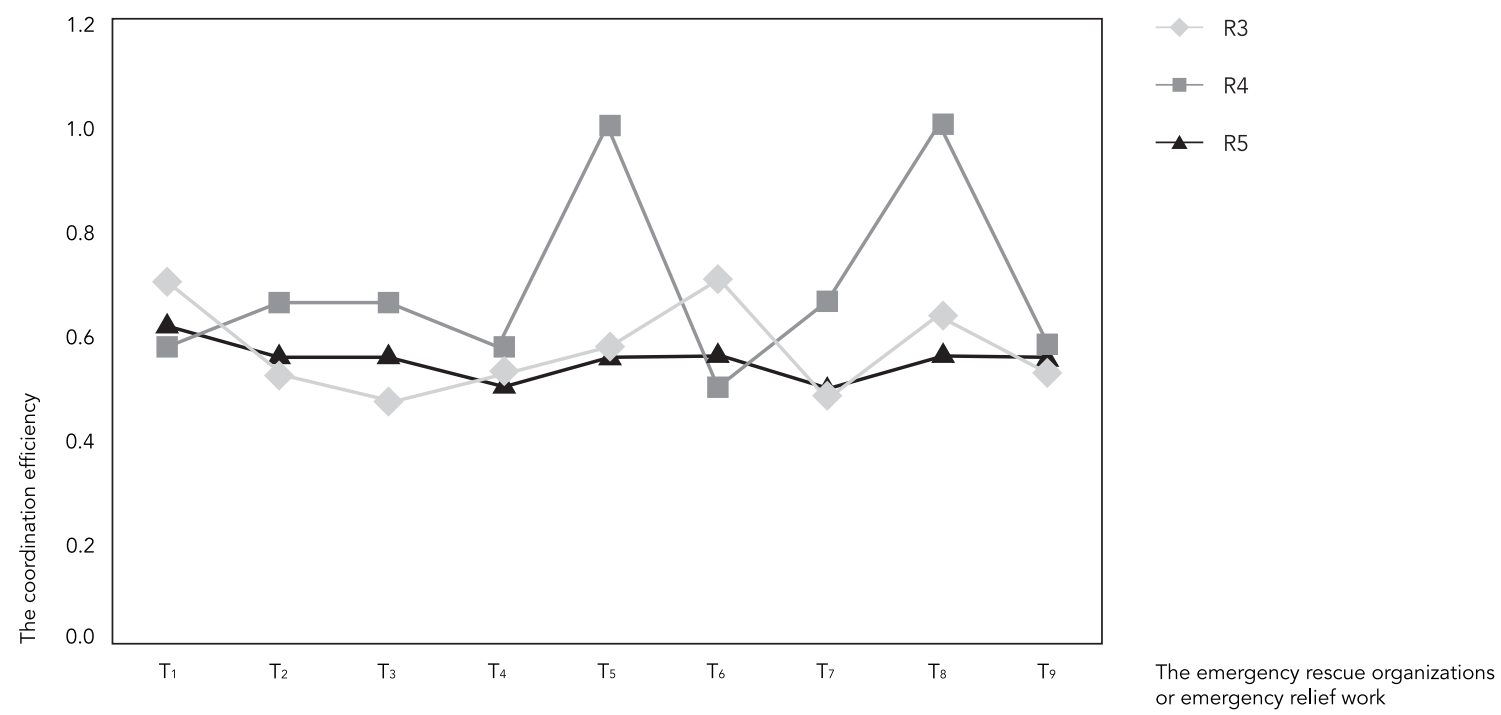

R3: represents the internal coordination efficiency for emergency relief work; R4: represents the collaborative efficiency between the rescue organizations and rescue work; and R5: represents the collaborative efficiency between the third layer rescue organizations and rescue work; $T_{1}$ : disaster analysis and investigation; $T_{2}$ : health and epidemic prevention; $T_{3}$ : infrastructure repair; $T_{4}$ : search and rescue; $T_{5}$ : emergency medical treatment; $T_{6}$ : resettlement of affected populations; $T_{7}$ : provision of psychological services; $T_{8}$ : preparation and transport of relief materials; $T_{9}$ : secondary disaster screening.

\section{Resumen}

El rescate de emergencia tras un terremoto es un trabajo complejo que requiere la participación de organizaciones sociales y especializadas en socorro. Estudiar la eficiencia en la coordinación de emergencia tras un terremoto, no sólo ayuda a las organizaciones destinadas al rescate en la definición de sus propias misiones de rescate, sino que también fortalece la comunicación interorganizacional y las tareas de colaboración, mejorando la eficiencia en el rescate de emergencia y reduciendo pérdidas. En este trabajo, se introduce la entropía colaborativa para estudiar las operaciones de rescate tras un terremoto; con el fin analizar la relación de coordinación en los rescates de emergencia, estudiar la relación de coordinación en los mismos, donde se establecen matrices colaborativas y funciones de entropía colaborativas entre el trabajo de las organizaciones de socorro y sociales, y donde la eficiencia colaborativa de los elementos de rescate está determinante basada en esta función de entropía. Finalmente, el terremoto de Lushan se usa como ejemplo para evaluar la eficiencia en la coordinación de un rescate de emergencia tras un terremoto.

Trabajo de Rescate; Emergencias em Desastres; Desastres Naturales 


\section{Contributors}

H. Rong was responsible for the conception and design of the study, data acquisition, analysis and interpretation, drafting the article, final approval of the version to be published, and agreed to be accountable for all aspects of the study in ensuring that questions related to the accuracy or integrity of any part are appropriately investigated and resolved. LXuledong. participated in the study's conception and design, data acquisition, critical revision for important intellectual content, and agreed to be accountable for all aspects of the study in ensuring that questions related to the accuracy or integrity of any part are appropriately investigated and resolved. Z. Guizhi participated in the data analysis and interpretation, critical revision for important intellectual content, and agreed to be accountable for all aspects in ensuring that questions related to the accuracy or integrity of any part are appropriately investigated and resolved. Y. Yulin worked on acquisition of data, drafted the article, approve the version to be published, agreed to be accountable for all aspects of the study in ensuring that questions related to the accuracy or integrity of any part are appropriately investigated and resolved. W. Da acquired the data, revised it critically for important intellectual content, approve the version to be published, agreed to be accountable for all aspects of the study in ensuring that questions related to the accuracy or integrity of any part are appropriately investigated and resolved.

\section{Acknowledgments}

This research is funded by the National Nature Science Foundation of China (71131006), China Postdoctoral Science Foundation Funded Project (2012M521705), Postdoctoral Science Special Foundation of Sichuan Province, Postdoctoral Science Special Foundation of Sichuan University and the Fundamental Research Funds for the Central Universities (skzx2013-dz07, skqy201223).

\section{References}

1. Schmidt k, Bannon L. Taking CSCW seriously: supporting articulation work. Computer Supported Cooperative Work (CSCW) 1992; 1:7-40.

2. Ball MO, Hoffman RL, Knorr D, Wetherly J, Wambsganss $\mathrm{M}$. Assessing the benefits of collaborative decision making in air traffic management. 3rd USA/Europe Air Traffic Management R\&D Seminar Napoli 2000; 6:1-11.

3. Lv X. Air traffic management collaborative decisions. Journal of AirTraffic management 2005; 4:4-5.

4. Naim K, Tolga A, Fatih D. Collaborative emergency management and national emergency management network. Disaster Prevention and Management 2010; 19:452-68.

5. Turner BA. The organizational and interorganizational development of disasters. Administrative Science Quarterly 1976; 21:378-97.

6. Quarantelli EL. Disaster crisis management: a summary of research findings. Journal of Management Studies 1988; 25:381-5.

7. Quarantelli EL. Ten criteria for evaluating the management of community disasters. Disasters 1997; 21:39-56.

8. Comfort LK, Kilkon K, Zagorecki A. Coordination in rapidly evolving disaster response systems: the role of information. Am Behav Sci 2004; 48:295-313.

9. Wu G, Zhang K. The empirical research on multiagent emergency coordination efficiency affecting factors: highway in Hubei province as an example. Engineering Research - Interdisciplinary Perspective of Engineering 2011; 3:164-73.

10. Deng F, Liu J. Research on emergency collaborative methods of plateau Earthquake: taking Yushu earthquake for example. China Safety Science 2012; 22:170-6.

11. Song Q. Earthquake emergency collaborative logistics network evolution and simulation-based on the CAS theory. Harbin: Harbin Engineering University; 2012.

12. Xie Z. The evolution mechanism of urban earthquake secondary disasters chain and collaborative emergency management mechanism. Chengdu: Southwest Jiaotong University; 2011.

13. Xu JP. Earthquake rescue recovery reconstruction systems engineering. Beijing: Science Press; 2011.

14. Liang X, Ge P, Yang Y, Bao B. Functions matching and selection for product design based on dependency constraints. China Mechanical Engineering 2011; 22:227-30.

15. Song H-L, Li J. Enterprise organization system collaborative evaluation based on information measure. Journal of Management Science in China 2009; 12:22-36.

16. Jiang DXL, Yue Y. The evaluation model based on collaborative entropy. Journal of Computer Integrated Manufacturing System 2012; 17:2522-8.

17. Wang Y. Emergency coordination decision-making evaluation and selection research. Harbin: Harbin Engineering University; 2011.

Submitted on 13/Mar/2014

Final version resubmitted on 04/Oct/2014

Approved on 31/Oct/2014 